\title{
Fourth Dimension
}

National Cancer Institute

\section{Source}

National Cancer Institute. Fourth Dimension. NCI Thesaurus. Code C94901.

Denoting a process that involves all 3 spatial dimensions in addition to some type of time information. 